Dermatology 2008;216:83-84

DOI: $10.1159 / 000109365$

\section{R501X and 2282del4 Filaggrin Mutations Do Not Confer Susceptibility to Psoriasis and Atopic Dermatitis in Italian Patients}

\author{
Emiliano Giardina a , Nicoletta Paolillo a, Cecilia Sinibaldi a, \\ Giuseppe Novelli ${ }^{\mathrm{a}, \mathrm{b}}$ \\ a Department of Biopathology and Centre of Excellence for \\ Genomic risk Assessment in Multifactorial and Complex \\ Diseases, School of Medicine, University of Rome 'Tor Vergata',

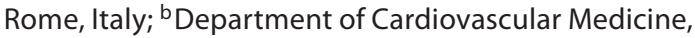 \\ University of Arkansas for Medical Sciences, Little Rock, Ark., \\ USA
}

Key Words

Psoriasis $\cdot$ Atopic dermatitis · Filaggrin $\cdot$ Complex disease

Psoriasis (PS) is a chronic inflammatory skin disorder characterized by keratinocyte hyperproliferation and altered differentiation. Atopic dermatitis (AD) is a common chronic inflammatory skin disease characterized by itchy inflamed skin. Genomewide linkage studies for PS/AD revealed a significant linkage to a region on chromosome 1q21 $[1,2]$, containing the epidermal differentiation complex (EDC). EDC is a cluster of genes with a key role in terminal differentiation of human epidermis. Recently we demonstrated a co-localization of the PS (PSORS4) and AD (ATOD2) susceptibility loci in a $42-\mathrm{kb}$ interval in Italian patients [3].

Most recently, it has been reported that two loss-of-function mutations - R501X and 2282del4 - within the filaggrin gene (FLG) located in the epidermal differentiation complex are associated with $\mathrm{AD}$ in several populations [4-6]. Loss-of-function mutations in FLG predispose to ichthyosis [7], which in its mild form shares clinical characteristics with PS and AD such as dryness and altered differentiation of keratinocytes. In the outer granular layer of the epidermis, filaggrin is associated with keratin intermediate filaments, supports their packing into bundles and plays a critical role in carrying out the protective task of epidermis. In terminally differentiated keratinocytes, filaggrin is cross-linked to the cornified cell envelope, which constitutes an insoluble barrier of the stratum corneum protecting the organism against environmental agents and preventing epidermal water loss. The loss of epidermal barrier function represents one of the first steps in the development of PS and AD and therefore FLG can be considered an obvious predisposing gene to both diseases.

Although FLG is located $1 \mathrm{Mb}$ from the susceptibility haplotype associated to both PS and AD in Italian patients [3], FLG null mutations were genotyped in a PS and AD cohort in order to evaluate either their involvement in the pathogenesis of both diseases or the existence of an epistatic relationship between Italian shared susceptibility haplotype (MIDDLE-ENDAL16) and FLG mutations. AD and PS patients selected either from trios analyzed in the previous work or newly recruited $\mathrm{AD} / \mathrm{PS}$ patients were screened. A total of 195 PS patients and 178 AD patients were analyzed; 210 blood donors from the same ethnic background and without a history of PS, AD or other autoimmune disorders were selected as controls. All PS patients had a dermatologist-confirmed diagnosis of chronic plaque psoriasis and most of them had type I psoriasis (70\%). As for AD patients a consensus diagnosis of the disease was assessed either by an expert dermatologist or by a pediatric allergologist. Written consent was obtained for all the patients or their parents.

$\mathrm{AD}$ was extrinsic in $68 \%$ of the cases with $52 \%$ of the patients showing early onset of the disease ( $<2$ years old). Specific sensitization was defined to be present if at least one of the specific IgE antibodies was positive (CAP-RAST class $\geq 1$, corresponding to $\geq 0.35 \mathrm{kU} / \mathrm{l}$ ). A raised total serum IgE was considered greater than $100 \mathrm{kU} / \mathrm{l}$. Extrinsic AD was considered as AD with sensitization and/or IgE levels $\geq 100 \mathrm{kU} / \mathrm{l}$.

The 2282del4 mutation was typed by sizing a fluorescently labeled PCR fragment on an Applied Biosystems 3130xl as previously described [7]. Genotyping of R501X was performed by TaqMan allelic discrimination assay (primer F: 5'-GCA CTG GAG GAA GAC AAG GAT-3'; primer R: 5'-CTC TTG GGA CGC TGA ATG C; probe 1: 5'-CTG TCT CGT GCC TGC-3'; probe 2: 5'-CTG TCT CAT GCC TGC-3'). Genotype assessment of both 2282 del4 and R501X was confirmed by direct sequencing of $10 \%$ of the samples. Screening of FLG mutations was performed as previously described [5]. A PCR fragment of $3697 \mathrm{bp}$ was amplified from human genomic DNA using forward primer FILF3 (5'-GCT GAT AAT GTG ATT CTG TCT G-3') and reverse primer RPT3P10R (5'-GAC CCC GAT GAT TGT TCC TGT-3'). This PCR fragment encompasses the $5^{\prime}$-end of exon 3 of the profilaggrin gene, repeats 1 and 2 and $401 \mathrm{bp}$ of repeat 3 . PCR conditions were as follows: $\left(94^{\circ} \mathrm{C} 5 \mathrm{~min}\right) 1,\left(94^{\circ} \mathrm{C} 30 \mathrm{~s}, 61^{\circ} \mathrm{C} 45 \mathrm{~s}, 72^{\circ} \mathrm{C}\right.$ $3 \mathrm{~min} 20 \mathrm{~s}) 31 \mathrm{cycles}$, and a final extension at $72^{\circ} \mathrm{C}$ for $5 \mathrm{~min}$. The 3,697-bp PCR fragment was sequenced with primers FILr3.F1 (5'-GGG TCA GGA CAC CAT TCG TGC-3') and RPT3P10R.

Genotyping of FLG mutations in PS patients revealed that the frequency of risk alleles of R501X and $2282 \mathrm{del} 4$ was $0.0 \%$, i.e. no mutant allele has been observed (table 1). Genotyping of R501X and 2282del4 mutations in AD patients and controls showed similar frequency of risk alleles: 0.6 vs. $0.0 \%$ and 0.9 vs. $0.5 \%$, respectively. Risk allele frequencies observed in the Italian AD patients were strongly reduced in respect to those described in other patients of European origin $[4,6]$. Following the above-mentioned results we searched for additional mutations in FLG. We resequenced $120 \mathrm{AD}$ patients and $100 \mathrm{PS}$ patients for $5^{\prime}$-end of exon 3 of the profilaggrin gene, repeats 1 and 2 and $401 \mathrm{bp}$ of repeat 3 . We did not observe additional mutations in FLG in either AD or PS patients. These results taken together with very recent data [8] seem to rule out an involvement of R501X and 2282del4 in PS and
KARGER

(c) 2008 S. Karger AG, Basel

Fax +41 613061234

E-Mail karger@karger.ch

www.karger.com
Accessible online at: www.karger.com/drm 
Table 1. Frequencies of wild-type/risk alleles of R501X and 2282del4

\begin{tabular}{llll}
\hline \multirow{2}{*}{ Variant } & Study group & \multicolumn{2}{l}{ Allele frequency } \\
\cline { 3 - 4 } & & wild-type & risk allele \\
\hline \multirow{2}{*}{ R01X } & psoriasis & $390(100 \%)$ & $0(0 \%)$ \\
& $\begin{array}{l}\text { atopic dermatitis } \\
\text { controls }\end{array}$ & $354(99.4 \%)$ & $2(0.6 \%)$ \\
& psoriasis & $420(100 \%)$ & $0(0 \%)$ \\
\hline & atopic dermatitis & $390(100 \%)$ & $0(0 \%)$ \\
& controls & $418(99.1 \%)$ & $3(0.9 \%)$ \\
\end{tabular}

$\mathrm{AD}$ in the Italian population. Although it should be further considered that another mutation located elsewhere in FLG could be involved in the susceptibility of PS and AD in the Italian population, we would like to outline that it will be important to investigate on the extremely low frequency of R501X and 2282del4 in the Italian samples. Previous reports showed that these two highly prevalent null mutations (R501X and 2282del4) in the beginning of FLG significantly predispose European individuals to earlyonset, severe, and persistent $\mathrm{AD}$ and also to the form of asthma associated with AD [4]. These results were replicated in several other European case-control association studies with similar conclusions [9]. The lack of association of R501X and 2282del4 in PS/AD Italian cohorts may reflect the existence of a negative selection of these FLG mutations in the Italian chromosomes or the existence of a different chromosome pool. In this perspective, the study of Italian as well as other 1q21-linked samples can be particularly useful both to disclose population-specific pathogenetic pathways for FLG and other 1q21 genes. It would be fundamental in the future to evaluate the worldwide distribution of FLG mutations in order to understand the genetic heterogeneity underlying the susceptibility to AD/PS mediated by FLG.

\section{Acknowledgments}

This work was supported by A.DI.P.S.O (Italian Association for the Defense of Psoriatic Patients) MIUR and the Italian Ministry of Health. We also thank Elena Galli, Ercole Brunetti, Antonio Costanzo, Sergio Chimenti, Loredana Chini, Viviana Moschee and Mauro Paradisi for their help in recruiting patients.

\section{References}

1 Cookson WO, Ubhi B, Lawrence R, Abecasis GR, Walley AJ, Cox HE, Coleman R, Leaves NI, Trembath RC, Moffatt MF, Harper JI: Genetic linkage of childhood atopic dermatitis to psoriasis susceptibility loci. Nat Genet 2001;27:372-373.

2 Capon F, Novelli G, Semprini S, Clementi M, Nudo M, Vultaggio P, Mazzanti C, Gobello T, Botta A, Fabrizi G, Dallapiccola B: Searching for psoriasis susceptibility genes in Italy: genome scan and evidence for a new locus on chromosome 1. J Invest Dermatol 1999;112:32-35.

3 Giardina E, Sinibaldi C, Chini L, Moschese V, Marulli G, Provini A, Rossi P, Paradisi M, Chimenti S, Galli E, Brunetti E, Girolomoni G, Novelli G: Co-localization of susceptibility loci for psoriasis (PSORS4) and atopic dermatitis (ATOD2) on human chromosome 1q21. Hum Hered 2006;61:229-236.

4 Palmer CN, Irvine AD, Terron-Kwiatkowski A, Zhao Y, Liao H, Lee SP, Goudie DR, Sandilands A, Campbell LE, Smith FJ, O'Regan GM, Watson RM, Cecil JE, Bale SJ, Compton JG, DiGiovanna JJ, Fleckman P, Lewis-Jones S, Arseculeratne G, Sergeant A, Munro CS, El Houate B, McElreavey K, Halkjaer LB, Bisgaard H, Mukhopadhyay S, McLean WH: Common loss-of-function variants of the epidermal barrier protein filaggrin are a major predisposing factor for atopic dermatitis. Nat Genet 2006;38:441-446.

5 Sandilands A, O'Regan GM, Liao H, Zhao Y, Terron-Kwiatkowski A, Watson RM, Cassidy AJ, Goudie DR, Smith FJ, McLean WH, Irvine $\mathrm{AD}$ : Prevalent and rare mutations in the gene encoding filaggrin cause ichthyosis vulgaris and predispose individuals to atopic dermatitis. J Invest Dermatol 2006;126:1770-1775.

6 Weidinger S, Rodriguez E, Stahl C, Wagenpfeil S, Klopp N, Illig T, Novak N: Filaggrin mutations strongly predispose to early-onset and extrinsic atopic dermatitis. J Invest Dermatol 2007;127:724-726.

7 Smith FJ, Irvine AD, Terron-Kwiatkowski A, Sandilands A, Campbell LE, Zhao Y, Liao H, Evans AT, Goudie DR, Lewis-Jones S, Arseculeratne G, Munro CS, Sergeant A, O’Regan G, Bale SJ, Compton JG, DiGiovanna JJ, Presland RB, Fleckman P, McLean WH: Loss-of-function mutations in the gene encoding filaggrin cause ichthyosis vulgaris. Nat Genet 2006;38:337-342.

8 Huffmeier U, Traupe H, Oji V, Lascorz J, Stander M, Lohmann J, Wendler J, Burkhardt H, Reis A: Loss-of-function variants of the filaggrin gene are not major susceptibility factors for psoriasis vulgaris or psoriatic arthritis in German patients. J Invest Dermatol 2007; 127:1367-1370

9 Irvine AD: Fleshing out filaggrin phenotypes. J Invest Dermatol 2007; 127:504-507.

Dr. Emiliano Giardina

University of Rome 'Tor Vergata', Department of Biopathology

Via Montpellier 1, IT-00133 Rome (Italy)

Tel. +39 067259 6072, Fax +390620427313

E-Mailemiliano.giardina@uniroma2.it 